LA-UR-97- $\because 506$

Approved for public release;

distribution is unlimited

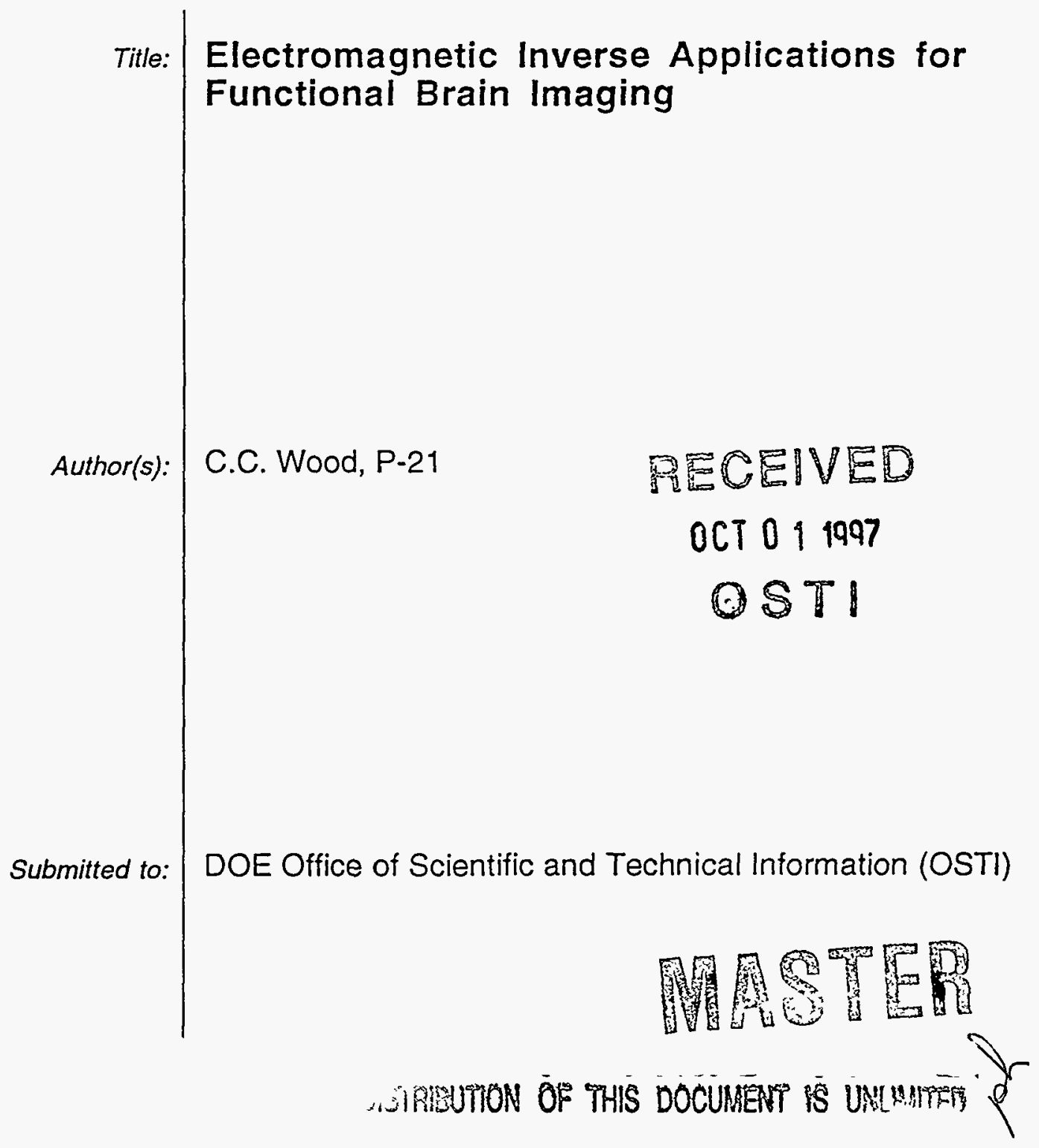

Los Alamos

NATIONAL LABORATORY

Los Alamos National Laboratory, an affirmative action/equal opportunity employer, is operated by the University of California for the U.S. Department of Energy under contract W-7405-ENG-36. By acceptance of this article, the publisher recognizes that the U.S. Government retains a nonexclustve, royaltyIree license to publlsh or reproduce the published form of this contribution, or to allow others to do so, for U.S. Government purposes. Los Alamos Nallonal Laboratory requests that the publisher identify this article as work performed under the auspices of the U.S. Department of Energy. Los Alamos National Laboratory strongly supports academic freedom and a researcher's right to publish; as an institution, however, the Laboratory does not endorse the vieupoint of a pubilcation or guarantee its technical correctness. 


\section{DISCLATMER}

Portions of this document may be illegible in electronic image products. Images are produced from the best available original document. 


\section{DISCLAIMER}

This report was prepared as an account of work sponsored by an agency of the United States Government. Neither the United States Government nor any agency thereof, nor any of their employees, make any warranty, express or implied, or assumes any legal liability or responsibility for the accuracy, completeness, or usefulness of any information, apparatus, product, or process disclosed, or represents that its use would not infringe privately owned rights. Reference herein to any specific commercial product, process, or service by trade name, trademark, manufacturer, or otherwise does not necessarily constitute or imply its endorsement, recommendation, or favoring by the United States Government or any agency thereof. The views and opinions of authors expressed herein do not necessarily state or reflect those of the United States Government or any agency thereof. 


\title{
Electromagnetic Inverse Applications for Functional Brain Imaging
}

\author{
Charles C. Wood ${ }^{*}$
}

\begin{abstract}
This is the final report of a one-year, Laboratory Directed Research and Development (LDRD) project at Los Alamos National Laboratory (LANL). This project addresses an important mathematical and computational problem in functional brain imaging, namely the electromagnetic "inverse problem." Electromagnetic brain imaging techniques, magnetoencephalography (MEG) and electroencephalography (EEG), are based on measurements of electrical potentials and magnetic fields at hundreds of locations outside the human head. The inverse problem is the estimation of the locations, magnitudes, and time-sources of electrical currents in the brain from surface measurements. This project extends recent progress on the inverse problem by combining the use of anatomical constraints derived from magnetic resonance imaging (MRI) with Bayesian and other novel algorithmic approaches. The results suggest that we can achieve significant improvements in the accuracy and robustness of inverse solutions by these two approaches.
\end{abstract}

\section{Background}

This project addresses an important mathematical and computational problem in functional brain imaging, namely the electromagnetic "inverse problem." Electromagnetic brain imaging techniques, magnetoencephalography (MEG) and electroencephalography (EEG), are based on measurements of electrical potentials and magnetic fields at hundreds of locations outside the human head. The inverse problem, then, is the estimation of the locations, magnitudes, and time sources of electrical currents in the brain from surface measurements. In its most general form, this problem is ill posed in the sense that multiple current distributions in the brain can give rise to the same electric potential or magnetic field distribution over the surface of the head. It is therefore not possible to calculate a unique current distribution in the brain from the electric potential or magnetic field over the head surface.

However, considerable progress has been made on this problem by two distinct approaches: (a) the introduction of constraints derived from independent information (e.g., from anatomical magnetic resonance imaging or MRI); and (b) the development of new algorithmic approaches to the problem based on recent developments in large-scale

\footnotetext{
- Principal Investigator, E-Mail: wood@biophysics.lanl.gov
} 
numerical methods. Our work combines the use of anatomical constraints derived from MRI with Bayesian and other algorithmic approaches to the inverse problem.

\section{Methods and Results}

First, we explored Bayesian and related formulations of the anatomically constrained inverse problem in which Bayesian "priors" are derived from anatomical MRI data collected as part of other programs in the Biophysics Group at Los Alamos National Laboratory (LANL). The Bayesian approach considers a posterior probability distribution that assigns all current distributions a relative likelihood based on how well each distribution fits the data and meets the specified prior probability distribution of "the priors."

Numerical summations were made over a range of combinations of the number and locations of current-generating regions using Monte Carlo techniques and the posterior likelihoods of each combination were computed. In order to calculate the posterior likelihood for a given set of regions, integrations over all possible current distributions that could be present in that region were computed; this integration can be done semianalytically if the prior distributions are Gaussian in form. This approach was assessed: (a) using a variety of simulated data sets generated with different numbers and locations of activation; and (b) using human MEG data in visual stimulation paradigms collected in other Biophysics Group projects. Results suggest that the Bayesian formulation holds considerable promise in cases where priors can be adequately estimated.

Second, we investigated the value of a multistart simplex approach to determination of bestfitting model parameters for multiple-dipole spatiotemporal data. This approach has the advantage that a range of starting parameter values is employed as compared to investigator-specified values in conventional nonlinear minimization approaches. Results suggest that the multistart method allows robust estimation of hest-fitting and near-bestfitting parameters when the assumptions of the underlying multiple-dipole model are adequately met by the data.

\section{Publication}

J.S. George et al., "Mapping Function in the Human Brain with MEG, Anatomical MRI, and Functional MRI," Journal of Clinical Neurophysiology 12, 406(1995). 